\title{
Book Review \\ Journalism that Matters: Views from Central and Eastern Europe. By Michał Głowacki, Epp Lauk and Auksė Balčytienė. Bern: Peter Lang, 2014, 214 pp.; ISBN: 978-3-631-65421-7 hb.
}

\author{
Elena Rodina \\ Department of Media, Technology, and Society, Northwestern University, Evanston, IL 60208, USA; \\ E-Mail: elenarodina2013@u.northwestern.edu
}

Submitted: 1 June 2015 | Accepted: 7 July 2015 | Published: 29 December 2015

\begin{abstract}
This book is a much-needed contribution to journalistic studies that allows us to have a closer and more nuanced look at media systems and press cultures in the countries of Central and Eastern Europe (CEE) from a non-Western perspective. The volume is of high value to anyone who is interested in the diversity that underlies the unifying term of "postcommunist media." Most of its authors rely on rich data collected throughout lengthy periods of time on the territory of Central and Eastern Europe, which allows us to see not only the current state of "Eastern" media, but its development throughout time.
\end{abstract}

\section{Keywords}

Central and Eastern Europe; de-Westernizing media studies; journalism; journalistic practices; media

\section{Issue}

This book review is part of the special issue "Turbulences of the Central and Eastern European Media", edited by Epp Lauk (University of Jyväskylä, Finland).

(C) 2015 by the author; licensee Cogitatio (Lisbon, Portugal). This article is licensed under a Creative Commons Attribution 4.0 International License (CC BY).

This book is a much-needed contribution to journalistic studies that allows us to have a closer and more nuanced look at media systems and press cultures in the countries of Central and Eastern Europe (CEE) from a non-Western perspective.

De-Westernizing media and communication studies has been high on the agenda of international scholars in recent years, and it is still a matter of debate to the academic community what exactly the idea of deWesternizing should imply. Waisbord and Mellado (2014) define this trend as two-fold: first, it means focusing more attention on non-Western media, expanding the conventional research boundaries on a geographic level, and second, it involves a challenge to conventional Western media theories that have been developed based almost exclusively on case studies of media in developed democracies. The book fulfills this task on both levels; its authors focus on an analysis of non-Western press, as well as offer alternative analytic models that help analyze non-Western media systems on their own terms, taking into account cultural, social, historical, and political peculiarities of the regions of CEE. More than that, this volume adds a third level to de-Westernization by giving a voice to scholars who themselves proceed from diverse, non-Western backgrounds. These voices make a valuable and timely contribution to contemporary discourse on media and communication.

"Journalism that Matters" consists of ten chapters and a brief introduction. The reader will find the chapters to be written in greatly varying styles, from essays designed as historical and even philosophical overviews of evolution of CEE media systems, to research papers based on rich qualitative and quantitative data, often collected in multiple countries over several years. The short, highly compressed chapters of this volume are comparable to tips of icebergs, suggesting that a more detailed and in-depth research lies hidden beneath the surface of the length-restrictions required for this anthology. 
While the chapters are not grouped thematically, aside from their common focus on media of CEE countries, they can be segregated into three major groups.

The first group includes articles that are focused on evaluating the effectivity of media systems in postCommunist spaces. Thus, Miklos Sukosd in Chapter 2, "'East of West': Media in Central and Eastern Europe, Eurasia, and China: multiple post-communisms and shifting geopolitical realities," describes three different social, political, and economic systems that developed after the collapse of the Communist systems, or "three post-communisms:" CEE, former Soviet States, and China. Sukosd explains how, throughout the years of media studies, Western media has traditionally served as an ideal point of comparison, a sort of benchmark that Central and Eastern Europe should strive for and achieve. He suggests that, by comparing non-Western and Western media, we are prone to sliding into reification of "Western democracy," instead of trying to understand the inner workings of non-Western media systems. His strategy is to focus on a comparison of a variety of post-Communist media systems, pointing out their commonality and mutual influences. In Chapter 3, "The watchdogs that only bark? Media and political accountability in Central and Eastern Europe," Vaclav Stetka examines how media in so-called "posttransformation countries" of the CEE region fulfill their role as "watchdogs of democracy." He analyzes the real political impact of investigative journalism in eight countries by tracking how many politicians were either sentenced or stepped down from their jobs after their corrupt activities were exposed in the press. This research shows that direct effects of the publication of investigative pieces are weak in almost all countries. The author suggests that the lack of tangible effects from the publication of investigative pieces discourages journalists to continue performing in-depth investigative work, and vice versa, concluding that one of the most important factors that would help investigative journalism flourish would be a presence of an effective system of other accountability institutions that would facilitate a subsequent prosecution of corrupt politicians. In Chapter 7, "Watchdog or underdog: how ethical is the Bulgarian media?" Bissera Zankova and Svetlozar Kirilov study media ethics (or rather the deficiency of such) in Bulgaria, analyzing ethics not as a set of given and easily transferable norms, but as rules that emerge through the complex interaction of media, structures of political, economic power, and the citizens. In Chapter 9, "Russian journalism as a social lift: comparing journalistic attitudes in the period 19922008," Svetlana Pasti explores the seemingly paradoxical data regarding Russian journalists: while the perception of their freedom has decreased over the past 20 years, the number of professionally satisfied journalists has increased. Pasti finds that the sources of growing journalistic satisfaction are power, wealth, and social mobility, and suggests that the character of these sources leads to the erosion of occupational ethics.

The second group of articles is focused on the journalistic changes that have been occurring in CEE countries due to the transition from "old" to "new" media. In his essay "How the internet changes journalism: some trends in the 'West' and 'East'" (Chapter 4), Peter Bajomi-Lazar proposes an historical perspective on the significance of the changes that the internet introduces to "Eastern" media, suggesting that proliferation of online media has not undisputedly improved its quality, due to the fact that media in the "East" has been facing technological changes while not yet being fully developed, in contrast to the media in the Western states. Bajomi-Lazar's ideas find further development in Chapter 8, "Journalism in crisis: the case of Serbia," where Miroljub Radojkovic, Ana Milojevic, and Aleksandra Ugrinic explore how the new information society challenges journalistic values and practices in Serbia. The authors demonstrate how the rapid spread of digital technologies, in combination with a global financial crisis, presents a strong challenge to fragile, still very much unconsolidated and unstable Serbian journalism. This view adds a new perspective to the popular concept of the democratizing role that the internet and computer technologies play in non-Western states. However, the "new technologies" theme appears to be the least developed in this particular volume, and these chapters demonstrate a lack of an in-depth, nuanced analysis that would show how the proliferation of new digital technologies deepens the journalistic crisis outlined by the authors.

The third and the most intellectually stimulating thematic group is formed by the chapters whose authors are interested in the analysis of non-Western journalistic practices and cultures. Agnieszka Stepinska and Michal Glowacki in "Professional roles, context factors, and responsibility across generations of Polish journalists" (Chapter 5) offer a fascinating study of journalistic self-perceptions in Poland, drawing comparison among the journalists of three age groups: the youngest generation of 20-30 years old, the "transformation generation" of 31-50 years old, and "pretransformation generation' of $50+$ years old. These three generations have practiced their journalistic profession in dramatically different conditions, and the study demonstrates how they express distinct journalistic values and professional self-perceptions. While the youngest journalists mostly relate to dissemination of news and serving the public interest, the members of the "transformation generation" see their role as "watchdog," and the oldest generation self-defining as "educators" and "news-disseminators." Interestingly, the youngest and the oldest generations of journalists prove to be more similar in understanding their professional roles, while the "middle" generation stands out. These findings demonstrate how varied journalistic cul- 
tures are not only around the globe and among the countries of $\mathrm{CEE}$, but within these countries as well, reminding us of the dangers of "glazing over" these differences. Agnieszka Milewski, Paulina Barczyszyn, and Epp Lauk in their paper "Three countries, one profession: the journalism cultures in Poland, Romania, and Moldova" (chapter 6) provide an insight into very different journalism cultures of the three closely situated countries, drawing a conclusion that, while theoretically media workers might assume the principles of a "liberal" model of journalism, what shapes their professional behaviors are contextual factors. The authors' findings disprove the notion that geographic proximity and a common Soviet past equates to a commonality of patterns in journalistic practices, therefore reinforcing the idea of the importance of conducting comparative analyses of "East and East," rather than "East and West" only. Finally, in Chapter 10, "Similar, but so different: the practices of press councils in Estonia and Finland," Epp Lauk seeks to answer the question of why the work of very similar structures of the Press Councils in Finland and Estonia yield dramatically different effects. While noting that Estonia has been consistently marked high on press freedom ratings, Lauk emphasizes how political media freedom does not always equal ethical use of this freedom. He suggests that Estonia, along with other post-communist democracies, does not yet possess the conditions of having an audience with a sufficient level of media literacy, and an ability of the media to discuss journalism quality publicly, which precludes them from having any effective ethical self-regulating mechanisms.

The essays collected in this book demonstrate a variety of approaches and methodological choices on the analysis of non-Western media cultures and systems. This book demonstrates both the fruitfulness of such an approach, as well as its challenges. It appears that, while some authors successfully manage to analyze media systems in non-Western contexts without applying normative Western models of analysis, others still slip into this normativity, viewing the journalistic cultures and structures of CEE in terms of their approximation to the Western standards. The overshadow of Siebert et al.'s Cold-war inspired "Four theories of press" is, unfortunately, often lingering in the background (and in the bibliographies) of some of the papers, not unlike the persistent ghost of Hamlet's late father. The articles that avoid labeling a variety of nonWestern journalistic practices as "good" or "bad" depending on how closely they are reminiscent of the Western media models prove to be the most profound and informative.

Another issue that recurs throughout the book is a disparity of terminology. While the authors of Chapter
1 name volatility and flux as being the main features of the media in CEE, it seems that similar instability could be attributed to the various authors' understanding of what sort of regimes these countries have. There is a whole range of definitions, including "young" and "new democracy," "neo-authoritarianism," "authoritarianism," "unconsolidated democracy," "hybrid regime," to name just a few. To be fair, this confusion is a reflection of the broader misunderstanding and disagreement among political scientists regarding the definition of the multiple post-Communist regimes, which do not remind Western democracies, but do not quite qualify as authoritarianisms either, and do not appear to cheerfully move towards democratic consolidation as they were expected to in the early 1990's. While political scientists are in need of such definitions due to the peculiarities of their field, communication and media scholars, perhaps, could circumvent this stage, and instead of providing confusing definitions of the regimes, go straight to in-depth analyses of concrete media cultures and practices.

Overall, this volume is of high value to anyone who is interested in the diversity that underlies the unifying term of "post-communist media." Most of its authors rely on rich data collected throughout lengthy periods of time on the territory of Central and Eastern Europe, which allows us to see not only the current state of "Eastern" media, but its development over time. The last two decades have been crucial for the development of journalistic cultures and societal values in post-Communist states, and a thoughtful analysis of the changes that have occurred during these years is valuable for academics, journalists, and the general public alike. The authors of this volume do not only answer many important questions about non-Western journalism, they expertly formulate new questions, inviting their colleagues, both 'Eastern' and 'Western' to join in the conversation. While some chapters offer more questions than answers (for instance, the second chapter's penultimate paragraph contains no less than seven questions in a row), they are all expertly formulated and deeply thought-provoking. I look forward for this conversation to be continued.

\section{Conflict of Interests}

The author declares no conflict of interests.

\section{Reference}

Waisbord, S., \& Mellado, C. (2014). De-westernizing communication studies: A reassessment. Communication Theory, 24(4), 361-372. 


\section{About the Author}

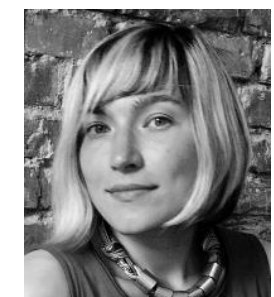

\section{Elena Rodina}

Elena Rodina is a PhD Candidate in the Department of Media, Technology, and Society at Northwestern University. Elena worked as a print journalist in Russia for over eight years. She covered a diverse range of social and political topics, including the consequences of Beslan school hostage crisis; political change in post-Castro Cuba; subcultures and gender issues in Chechnya, Kalmykia, and Yamal; interethnic marriage and ethnic conflict in the Far East. She is currently doing research on journalistic practices and media culture in Russia, focusing on the region of the North Caucasus. 